\title{
Potential contributions of wind power to a stable and highly renewable Swiss power supply
}

\author{
Bert Kruyt $^{\mathrm{a}, \mathrm{b}, *}$, Michael Lehning ${ }^{\mathrm{a}, \mathrm{b}}$, Annelen Kahl $^{\mathrm{b}}$ \\ ${ }^{a}$ WSL Institute for snow- and avalanche research SLF, Davos, Switzerland \\ ${ }^{b}$ Ecole Polytechnique Fédérale de Lausanne (EPFL), School of Architechture, Civil and Environmental Engineering (ENAC), Lausanne, Switzerland
}

\begin{abstract}
Using data from two measurement networks, we analyse the following aspects of wind speeds over Switzerland to assess the possibility of high wind power penetration: spatial correlation, persistent low wind power conditions and the diurnal and seasonal wind speed patterns. We show that correlation amongst speeds as a function of distance is significantly lower compared to values found in literature. This can be attributed to the complex terrain of the Alps, which has a profound influence on meteorological parameters. Secondly, using extreme value analysis we calculate return levels for low wind power periods. Large differences are found, with return levels ranging from 29 to 1017 hours of no power production for a return period of 10 years. No clear spatial pattern was found that can account for these values. However, the length of no-production periods decreases with increasing elevation. Next, we investigate diurnal and seasonal wind speed patterns and show how the different patterns and their intra-annual variation can be explained by local topography. We also find that with increasing elevation mean wind speeds and power production increase, even when accounting for lower air density. Wind speeds are on average higher in winter, and at elevation the relative increase in winter compared to summer is higher. Notable exceptions are explained from topography and carry implications for wind power development. In view of Switzerland's electricity shortage in winter, these findings make a strong claim for wind power development, especially at higher elevations.
\end{abstract}

Keywords: Wind energy, Correlation, Extreme value analysis, Persistence, Valley winds, Wind power integration

\section{Introduction}

In 2011, following the Fukushima Daiichi nuclear disaster, the Swiss Federal council and Parliament decided on the 28 phase out of Switzerlands five nuclear energy plants [5]. As 29 nuclear energy is responsible for $37,9 \%$ of Switzerlands an- 30 nual (2014) electricity supply [13], this phase out implies a ${ }_{31}$ major overhaul of the Swiss electricity supply. To this end, 32 the Federal council has developed the Energy Strategy 2050 which - amongst others- encompasses an expansion of electric- 34 ity production from renewable sources (wind, solar, hydro and ${ }_{35}$ geothermal).

Rapid expansion of weather dependent renewable electric- ${ }_{37}$ ity sources can however lead to undesired side effects. In Ger- 38 many, where solar and wind power have seen a significant in- 39 crease over the last decade, negative prices and high consumer 40 costs are amongst such effects [29, 43]. With a high share ${ }_{41}$ of wind power $(15 \%$ of total German electricity consumption 42 in 2015) [1], the ability to dampen fluctuations in production ${ }_{43}$ is also reduced. In extreme cases neighbouring countries are ${ }_{44}$ called upon to help smoothen out spikes in power production, ${ }_{45}$ as happened during a storm in March 2015, when the German TSO requested neighbouring countries to absorb German wind electricity in order to stabilise the German transmission grid [58]. While in this case the neighbouring countries were able

\footnotetext{
${ }^{*}$ Corresponding author

Email address: bert.kruyt@epf 1 .ch (Bert Kruyt)
}

\author{
,
} a strong correlation between wind speeds on those geographic scales [33]. Recently, much research has therefore focussed on the integration of renewables into the grid (see for example $[10,51,66])$ and the associated costs $[11,12]$. Switzerland differs from the general European case due to the presence of large amounts of hydropower ${ }^{1}$, which has been shown to increase the market value of wind energy [38], as hydropower allows for the compensation of short-term mismatches [25].

With current wind power penetration levels in Switzerland ( $0,14 \%$ of 2014 power production / $0.17 \%$ of consumption) [56, 13] it appears most economical to locate the capacity based on maximum annual yield, ignoring the temporal generation profile, since the installed capacity is relatively small. Imports can be called upon when no wind power is delivered and demand is high. However as both Switzerland and the EU are expected to increase their wind capacity in the coming decade ${ }^{2}$, the temporal generation profiles and their correlation will become increasingly important. The case of Germany exempli-

\footnotetext{
${ }^{1} 56,4 \%$ of annual (2014) electricity supply, $31.7 \%$ of which consists of storage hydropower [13]

${ }^{2}$ The European Wind Energy Agency estimates installed wind capacity in the EU to reach between 251 and $391 \mathrm{GW}$ in 2030 (between 19 and $33 \%$ of the EU's 2030 demand) [22]. In Switzerland, wind power is projected to produce between 500 and $1700 \mathrm{GWh}$ in 2035, when demand for electricity will be in the range of 55 to $60 \mathrm{TWh}(0,8$ to $3 \%)$ [56]
} 
fies that placing capacity based on maximum annual yield can ${ }_{103}$ become harmful to the system once penetration rates of renew-104 ables reach certain levels. Although it makes sense from an in-105 dividual investor's perspective to locate capacity based on max-106 imum annual yield (especially given current feed in tariffs), for ${ }_{107}$ the system as a whole it may be beneficial to consider other ${ }_{108}$ spatio-temporal statistics when allocating renewable sources. ${ }_{109}$

The purpose of this work therefore is to explore those wind ${ }_{110}$ speed statistics over Switzerland that are relevant in case of ${ }_{111}$ high penetration rates of wind power. Specifically three ele-112 ments are investigated: Firstly, we look into the correlation be-113 tween wind speeds throughout the country, because this is re-114 lated to the ability to smoothen overall wind power production.115 Secondly, using extreme value analysis, we examine the occur-116 rence of long periods where wind speeds are outside the tur- -117 bine's operating range (i.e. either too high or too low). Such $a_{118}$ probabilistic assessment sheds light on the worst case scenarios ${ }_{119}$ that are to be expected. Lastly, we investigate the diurnal wind ${ }_{120}$ speed patterns across the country, and look into their seasonal ${ }_{121}$ variation. Given that demand for electricity is subject to signif-122 icant diurnal and seasonal fluctuation, in a future Swiss power ${ }_{123}$ system with large shares of renewables, the temporal produc-124 tion patterns of non-dispatchable renewable sources are crucial $_{125}$ to minimise mismatch betweeen (residual) demand and supply.126 For all three aspects mentioned above, we try to assess the in- 127 fluence of the highly complex topography on the results. In $_{128}$ so far as these themes have been reseached, most studies have ${ }_{129}$ considered non-complex terrain. Given the profound influence ${ }_{130}$ of topography on meteorological parameters [68], there is lit-131 tle reason to assume the results of these studies could apply to 132 complex terrain as well.

The correlation $\rho$ between wind speeds as a function of dis-134 tance $d$ is typically related to a decay parameter $D$, which de-135 termines how fast the correlation decays with distance [33].136 Giebel [33] finds a decay parameter of $D=723 \mathrm{~km}$ for correla- ${ }_{137}$ tion between wind stations across Europe. Holttinen [39] finds 138 a value of $D=500 \mathrm{~km}$ for Scandinavian countries, and Katzen-139 stein et al. [42] estimate $D=350 \mathrm{~km}$ for Texan wind power time ${ }_{140}$ series. Villanueva et al. [68] describe a linear relation between ${ }_{141}$ correlation and distance, and compare correlations in both com-142 plex and non-complex terrain. They conclude that a linear re-143 lation between correlation and distance is a decent approxima-144 tion in both cases. Reducing output variation therefore typically ${ }_{145}$ requires combining wind farms over distances in these orders 146 of magnitude, where the relative variability of wind power de-147 creases as the area considered as an interconnected system in-148 creases [32]. However, the terrain in these studies is relatively ${ }_{149}$ flat. Given the aforementioned influence of topography on me-150 teorological parameters, it is unlikely that the values found in $_{151}$ these studies apply to more complex topography (such as that of $\mathrm{f}_{152}$ Switzerland [69]). So far, no comparison between correlation ${ }_{153}$ of wind speeds in complex terrain with these existing studies ${ }_{154}$ has been made. With this study we aim to fill that gap.

Next, we examine the occurrence of long periods where wind ${ }_{156}$ speeds are outside of the turbine's operating range and conse-157 quently, no power can be produced. While short term fluctu-158 ations (in the order of minutes to hours) may be balanced by ${ }_{159}$ hydropower production [25], sustained periods with low wind speeds have a strong impact on power systems that are highly dependent on wind power production. Often, wind speed persistence is investigated using the autocorrelation function, conditional probability or speed duration curves [15] [44] [45], but also runs analysis and intensity-duration analysis [48]. Recently, Telesca et al. [64] investigated the temporal structure of high frequency wind series in Switzerland, and found cyclic components of 24,12 , and sometimes 8 or 6 hours, that they relate to temperature and pressure variations. We will use extreme value analysis (EVA) to make inferences about long periods of low wind power conditions, because EVA allows for estimates beyond the length of the observed dataseries. Extreme value analysis is often used to describe extremes of processes in nature such as snowfall [8][7][6], rainfall [65], and wind speeds [59], but also financial processes and value at risk [61]. Its basic premise is to separately model the tail of a distribution. Although the magnitude of extreme wind speeds in Switzerland and elsewhere has been investigated before [17, 28, 47, 55], to our knowledge no effort has been undertaken to map the extremes of low-wind persistence in Switzerland, or relate these to power production.

Lastly, we examine the seasonal and diurnal evolution of wind speeds across Switzerland as well as elevational trends. Given the varied and complex terrain found across the country, it is possible that the (evolution of) wind speeds will be affected by this. For example, Chow [18] describes diurnal mountain wind systems or thermally driven winds: Due to the heating and cooling of the lower atmosphere, winds form that are driven by buoyancy. Mainly during stable summer weather, daytime heating in valleys will produce an up-valley flow. Nighttime cooling in its turn, will produce downwind flows, as cooler, heavier air flows down-slope. In section 3.3, we will investigate the evolution of the diurnal wind speed patterns over Switzerland, and infer implications for wind power production.

Apart from a diurnal evolution, there is also a seasonal pattern to the Swiss electricity demand that is mainly associated with an increase in lighting and heating in winter [3]. Combined with reduced hydropower production in winter due to the characteristics of the hydrological cycle, this leads to a power deficit in winter [63]. We will therefore also investigate the seasonal evolution of diurnal cycles, and see to what extent wind power is able to meet this demand. This is especially relevant given the fact that solar power declines significantly in winter due to the earth's inclination, and as such is unable to complement hydropower in its seasonal cycle. Mean wind speeds in Europe, on the contrary, are reported to increase in winter [37]. We will investigate if this also holds for the complex terrain in the Alps.

The paper is structured as follows: In the next section we describe the two main datasets that were used as well as the data processing that was done and the methods to calculate correlation, return levels and diurnal patterns. Next, in section 3 we discuss the results. We analyse some of the sensitive parameters with regards to the calculation of return levels in section 4. In section 5 we present our conclusions. 

Switzerland.

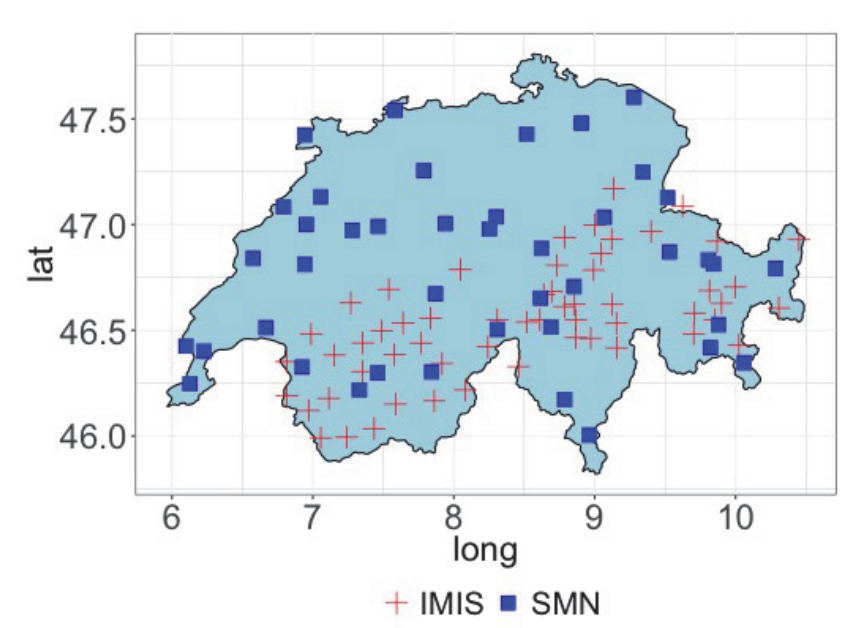

\section{Data and Methods}

\subsection{Measurement stations}

The Swiss weather service MeteoSwiss deploys a network ${ }_{199}$ of roughly 160 automated measuring stations across Switzer-200 land, called SwissMetNet (from here on SMN) [52]. We've ${ }_{201}$ manually selected the stations with long measurement series 202 (minimum of 35 years) of hourly wind speeds, which gives $\mathrm{us}_{203}$ a dataset of 42 stations. These stations are located throughout 204 Switzerland, at altitudes ranging from 273 (Lugano) to $3302_{205}$ m.a.s.l. (Piz Corvatsch). A second dataset is formed by the ${ }_{206}$ IMIS station network [50,60]. This network, consisting of $198_{207}$ stations around the Alps and Jura mountains, is operated by the ${ }_{208}$ Swiss Institute for Snow and Avalanche Research SLF. These ${ }_{209}$ stations are located in pairs with a wind station at an exposed $d_{210}$ location and a snow station at a less exposed location, which is ${ }_{211}$ generally also at slightly lower elevation. All stations measure ${ }_{212}$ temperature, humidity and wind speed. Data are averaged ${ }_{213}$ over 30 minutes. For our purposes, we use the wind stations,,$_{214}$ and only use the snow stations to interpolate missing data $\mathrm{in}_{215}$ the wind stations (see next section). These wind stations are a $_{21}$ located at elevations from 1936 (Amden - Mattstock) to 3345 (Zermatt - Platthorn) m.a.s.l. In total this gives us 62 of these stations, of which we use the 57 that have data sets longer than 5 years. Figure 1 shows both the IMIS and SMN stations in ${ }^{218}$
Figure 1: The SMN and IMIS stations

Most wind speed time series contain missing data, for exam-238 ple due to icing of the anemometers [34]. Since the continuity 239 of the time series is important to infer results about persistence, 240 we want to work with continuous data as much as possible. For 24 the IMIS stations, the presence of a second station (snow sta-242 tion) close to the wind station provides a useful set to base our 243 estimates of missing data on. Here, missing values are imputed 244 with the Amelia package in R [40][41]. This package estimates245 missing values based on an Expectation-Maximization with 246 where both the corresponding snow station and the nearest SMN station are also without data, not all missing values have been resolved. Intially the average missing data per series was $8.9 \%$ (with a median and max of $7.6 \%$ and $23.4 \%$ resp.). After imputation, these percentages are 0.4, 0.3 and 2.3\% respectively. We then average the IMIS values over the hour, so that both datasets have hourly resolution and can be easily combined. For the calculation of correlation coefficients and the calculation of diurnal wind patterns, we use this dataset and ignore the entries with missing values. For the calculation of return levels, the remaining missing values are replaced with the mean, because leaving them as zero or missing would distort the calculation as they would be regarded as being below the cut-in speed, and this could falsely introduce long periods of no wind power.

\subsection{Correlation}

Cross-correlation between measurement stations describes the degree to which two time series change in the same direction and magnitude. It is usually quantified using Pearson's correlation coefficient. Several authors have fitted an exponentially decaying function to describe correlation between wind speeds as a function of distance [33], [39], [42]. These functions have mainly been of the form

$$
\rho=e^{-d / D}
$$

where $\rho$ is the correlation coefficient, $d$ is the distance and $D$ the decay parameter that describes how fast the correlation decreases with distance. The latter is usually determined by fitting equation 1 to the data.

\subsection{Turbine choice}

The power a wind turbine produces at a certain speed is described by a turbine's power curve, which is specific for each turbine. In this work, we use the Enercon E82 turbine with a capacity of $2 \mathrm{MW}$, the cut-in speed at which the turbine starts to produce electricity, and the cut-out speed, at which the turbine is shut down to prevent damage. This turbine is widely used in Switzerland (a full list of current installations can be found on-line at [53]). It has a relatively low cut in speed of 2.5 $\mathrm{m} / \mathrm{s}$, which is thought to be favourable in low(er) wind conditions such as Switzerland. Using the same turbine for all locations arguably leads to sub-optimal results, since a higher power yield could be achieved by optimising the turbine selection for the wind characteristics of each location. As the selection of a turbine for a specific site is not straightforward however, this is beyond the scope of the present work. Since the goal is to compare locations rather than find the optimal yields, using one turbine seems plausible. 
The wind data is recorded at $10 \mathrm{~m}$, whereas most turbines are ${ }^{295}$ in the height range of 75-100 meters. Therefore a transforma- ${ }^{296}$ tion has to be made to make these speeds comparable. The ver- ${ }^{297}$ tical wind profile is often represented as following a logarithmic ${ }^{298}$ or power law [23] [26], the latter being given by

$$
v_{h h}=v_{10}\left(\frac{h h}{10}\right)^{\alpha}
$$

with $v_{h h}$ the speed at hub height hh, $v_{10}$ the speed measured ${ }_{304}^{303}$ at a height of 10 meter and $\alpha$ the wind shear coefficient. For neutral stability, a rule of thumb is to use a value of 0.143 or $_{306}$ $1 / 7$ for $\alpha$, although it is acknowledged that this may underesti- ${ }_{307}$ mate energy yield [46] (and references therein), as $\alpha$ is neither ${ }_{308}$ constant over height nor over time. Indeed, a range of (average) (no $_{309}$ values for $\alpha$ have been reported, from 0.1 in a mountain pass in ${ }_{310}$ Switzerland [19] to 0.36 for a Mediterranean island [30]. When ${ }_{31}$ intra-annual values of $\alpha$ are considered, it becomes clear that ${ }_{312}$ great variation during the year takes place. Kubik et al. $[46]_{313}$ finds values ranging from -0.5 to 0.5 , with a mean of 0.119 , $\mathrm{as}_{314}$ well as a clear diurnal pattern, where night time shear values are ${ }_{315}$ almost twice the daily values. Clifton et al. [19] find negative ${ }_{316}$ values for south-easterly winds at a pass location, and Farrugia [30] reports higher shear exponents during night-time and ${ }_{318}$ during winter. Furthermore, Bunse and Mellinghoff [14] show $_{319}$ that the distribution for $\alpha$ is broader in flat terrain than it is in $_{320}$ complex terrain, and concludes no general trend towards lower values of $\alpha$ in complex terrain. Lastly, it has been noted by several authors that in complex terrain, the vertical wind profile does not always follow a logarithmic- or power law [16] [24] and that this may lead to errors in power estimates of up to $50 \%$ [31]. In absence of a clear parametrisation of $\alpha$, we stick to the common-yet-disputable value of 0.14 . Rather than transforming the entire wind speed time series from $10 \mathrm{~m} \mathrm{to}_{323}$ hub height, we transform the turbine's power curve (and thus ${ }_{324}$ the cut-in and cut-out speed) down to $10 \mathrm{~m}$, for an assumed hub ${ }_{325}$ height of $80 \mathrm{~m}$. This is done solely for computational purposes, ${ }_{326}$ as transforming these two is less time consuming than transforming all multi-year time series. This then gives us a direct ${ }_{328}$ translation from measured wind speeds at $10 \mathrm{~m}$ to power output ${ }_{329}$ of a hypothetical wind turbine with a hub height of $80 \mathrm{~m}$.

\subsection{Extreme Value Analysis}

Extreme value analysis deals with the statistical behaviour ${ }^{33}$ of the extremes of a distribution of random variables [35]. ${ }^{334}$ For a sequence of independent and identically distributed ran- ${ }^{33}$ dom variables $X_{1}, X_{2}, . ., X_{n}$ the maximum is given by $Z_{n}={ }^{336}$ $\max \left(X_{1}, \ldots, X_{n}\right)$. Given that $n$ is large enough, the probability that $Z_{n}$ does not exceed a level $z$ is given by the Generalised ${ }^{338}$ Extreme Value (GEV) distribution, whose cumulative distribu- ${ }^{339}$ tion function is given by

$$
G(z ; \mu, \sigma, \xi)= \begin{cases}\exp \left[-\left(1+\xi \frac{z-\mu}{\sigma}\right)^{-\frac{1}{\xi}}\right] & \text { for } 1+\xi \frac{z-\mu}{\sigma}>0 \\ 0 & \text { otherwise }\end{cases}
$$

where $\mu, \sigma$ and $\xi$ are the location, scale and shape parameter, respectively. The sign of the shape parameter $\xi$ tells us whether the distribution is bounded $(\xi<0)$, in which case the value of $X$ is limited and theoretically no value above an upper bound can be observed. When the distribution is light tailed (i.e. $\xi=0$ ), extreme values are possible albeit not very likely. Lastly, in the case of a heavy tailed distribution $(\xi>0)$, extreme values are more likely to occur. These three cases of the GEV distribution are also known as the Weibull-, the Gumbel and the Frechet distribution respectively. For a visual representation of the GEV parameters, see [7]. Two main methods exist for dealing with maxima. Traditionally, the data is separated into blocks (e.g. months) and the GEV distribution is fitted to the monthly maxima. Hence this method is referred to as the block maxima method. The obvious downside here is that a lot of extremal data is discarded. The so-called peaks-over-threshold (POT) method on the other hand, takes into account all values above a certain threshold $u$. Given that the threshold is sufficiently high, the distribution of threshold exceedances can either be described by a generalised Pareto distribution (GPD), or by a Poisson Point (PP) Process. The latter has the advantage that by rescaling the intensity function of the Poisson process, the parameters can be made identical to those of the GEV. (For details see [20] or [21]). This allows for the computation of the return level $z_{p}$, a value that is exceeded on average once every return period $1 / p$. As such, a return level represents the $(1-p)$ th quantile of the GEV distribution. By inverting equation 3 we can obtain its value:

$$
z_{p}= \begin{cases}\mu-\frac{\sigma}{\xi}\left[1-\{-\log (1-p)\}^{-\xi}\right] & \text { for } \xi \neq 0 \\ \mu-\sigma \log -\log (1-p) & \text { for } \xi=0\end{cases}
$$

Of relevance to power production are the periods when no power is produced because the wind speed is either below the cut-in speed, or because the wind speed is above cut out speed. To assess these, we record the length of the intervals where the wind speed is outside of the turbine's operating range (i.e. below cut-in or above cut-out). With the distribution of these interval lengths, a Poisson point process is fitted to the exceedances over a threshold, for which the 90th percentile is used. Since we are modelling the interval length rather than wind speed, these data are independent. An important issue is the role of declustering in these series. Is the end of a nopower interval defined by one hour of power production, or do we need several consecutive hours of power production before a no-power interval is over? The consequences for the power system of a single hour of power production in between large intervals of no power can be argued to be insignificant. Therefore the declustering is run with a declustering parameter [62] of 3 hours. This means that wind speeds will have to be above the cut-in threshold (or below cut-out) for a minimum of 3 hours in order to separate no-power production intervals. Increasing this parameter leads to larger clusters of no-power events and as such will have a profound impact on the results. (see figure 2. The parameter choice is thus an important one, although there is no obvious choice. (For now we keep the decluster- 


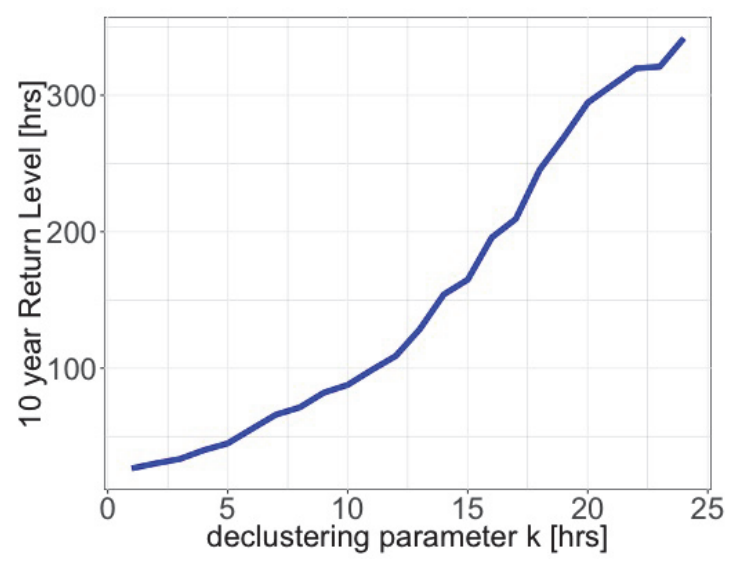

Figure 2: The Return level (in hours) as a function of the declustering parameter k. Shown here for the location Chasseral, in the Bernese Jura region of Switzerland.

ing parameter $k<<$ threshold $u$ ). No power production due to $\mathrm{to}_{38}$ forced downtime is not considered here. The return periods for $_{382}$ no production because of low or high winds are difficult to com- $_{383}$ pare to production losses because of turbine service or material ${ }_{384}$ damages. However, most turbines require on the order of days ${ }_{385}$ of service time with a yearly return period [36] but - more im- ${ }_{386}$ portantly - not all turbines of a farm will be off production at the ${ }_{387}$ same time. Therefore, we neglect the service and repair produc- ${ }_{388}$ tion losses in our analysis. Although it is acknowledged that in $_{389}$ highly turbulent environments, fatigue loads may be higher [9], ${ }_{390}$ which could lead to shorter turbine life or increased downtime, ${ }_{391}$ the magnitude of such effects is highly site-specific.

\subsection{Diurnal wind speed patterns}

To investigate the diurnal wind patterns at different stations, 394 data were processed as follows. Hourly time series for both station networks were averaged by hour of the day to produce ${ }^{395}$ annual averaged diurnal profiles. Secondly, the averaging was ${ }^{396}$ done per month and per hour of the day, so that intra-annual ${ }^{397}$ difference could be explored.

\section{Results and Discussion}

\subsection{Correlation}

Figure 3 shows the cross-correlation coefficients as a func-405 tion of the distance for 99 wind measurement stations from both 406 the IMIS and SMN network in Switzerland. Also shown are 407 some of the functions found in literature describing the rela-408 tion between wind speed (or power) correlation and distance as 409 discussed in the introduction.

Upon a first glance at the data in figure 3, fitting an expo-411 nential curve does not appear very obvious. And indeed, when ${ }_{412}$ we do, although we find a decay parameter $D$ of $44 \mathrm{~km}$, the ${ }_{413}$ $R^{2}$ value of -0.65 tells us this is a worse fit than a horizontal ${ }_{414}$ line. A linear fit is hardly better with an $R^{2}$ of 0.04 . From ${ }_{415}$ a visual assessment we can conclude that the correlations ${ }_{416}$ between wind speeds as a function of distance are significantly $y_{417}$

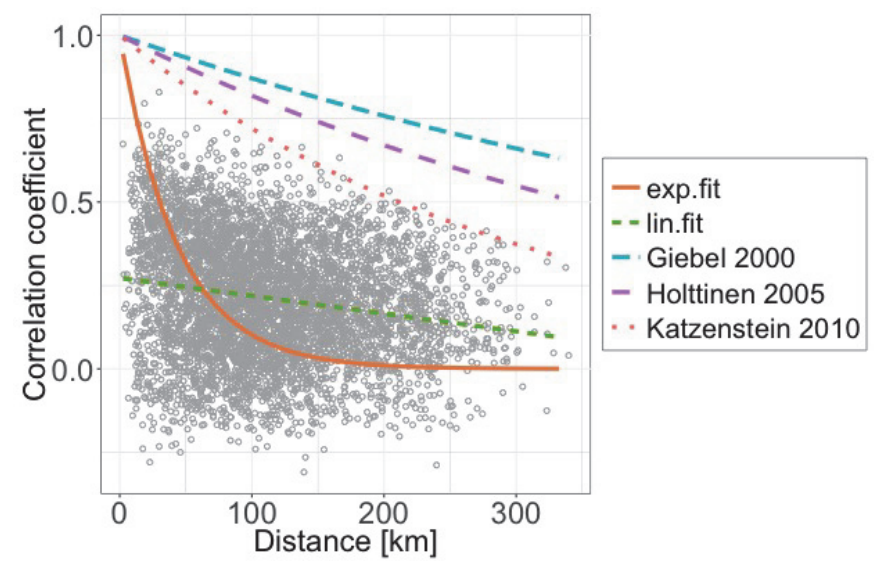

Figure 3: Cross-correlation between wind speeds in Switzerland. Also shown are the fitted functions, as well as the other values found in literature describing this relation $[33,39,42]$.

lower in Switzerland when compared to the values found in literature. What is furthermore noteworthy, is the fact that a significant number of negative correlations are found, indicating anti-correlation. This finding is interesting in view of combining wind farms to reduce overall output variability. It should be noted that because of the non-linear relation between wind speed and power output, correlation between power production is not (exactly) the same as correlations amongst wind speeds. Generally, correlations between power are lower (in the case of Giebel [33] $\mathrm{D}=723$ for speed and 641 for power). However, even with this remark, the above conclusion that correlations in Switzerland are lower still holds.

\subsection{Return levels}

Figure 4 shows the return levels for return periods of 10 and 50 years, in hours of no power production. This can be interpreted as the level being exceeded once every $10(50)$ years. It ranges from 29 to 1017 hours (roughly 6 weeks) for a return period of 10 years. For the return period of 50 years, the range spans from 34 hours to 1964 hours (figure 4). The highest 10 year return level is found in Disentis/Sedrun (1197 m.a.s.l.), in the central part of Switzerland, whereas the lowest return level was found at Sidelhorn, a summit close to the Grimsel pass on the border of the cantons of Bern and Valais. At a first glance, no clear spatial pattern seems apparent. A investigation into the relation between altitude and the parameters of the fitted Poisson Point process is shown in figure 6. It can be seen that there is a correlation between a station's elevation and the parameters of the fit, which leads to a correlation between the 10 year return level and elevation. We can also see that the majority of stations have an unbound distribution, indicated by the positive value of $\xi$. For a couple of stations the parameter $\xi$ is negative, indicating a bound distribution. If we closer examine the 14 stations with a significant negative $\xi$ parameter $(\xi<0.01)$, we find that these are mainly stations above 2200 m.a.s.l, except for two stations in the (far) western part of Switzerland at lower elevations (the only two SMN stations in the lower right panel 

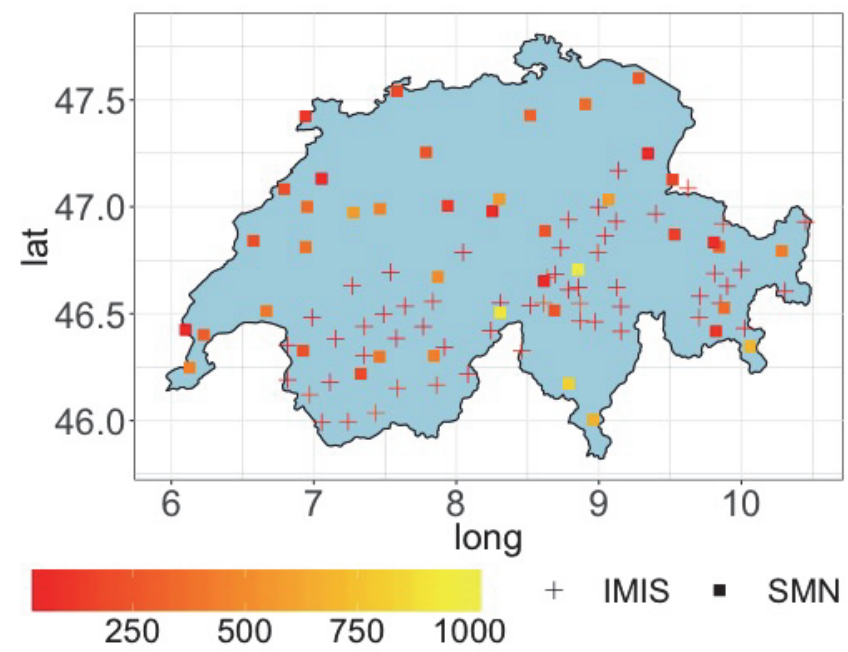

(a) 10 year return level

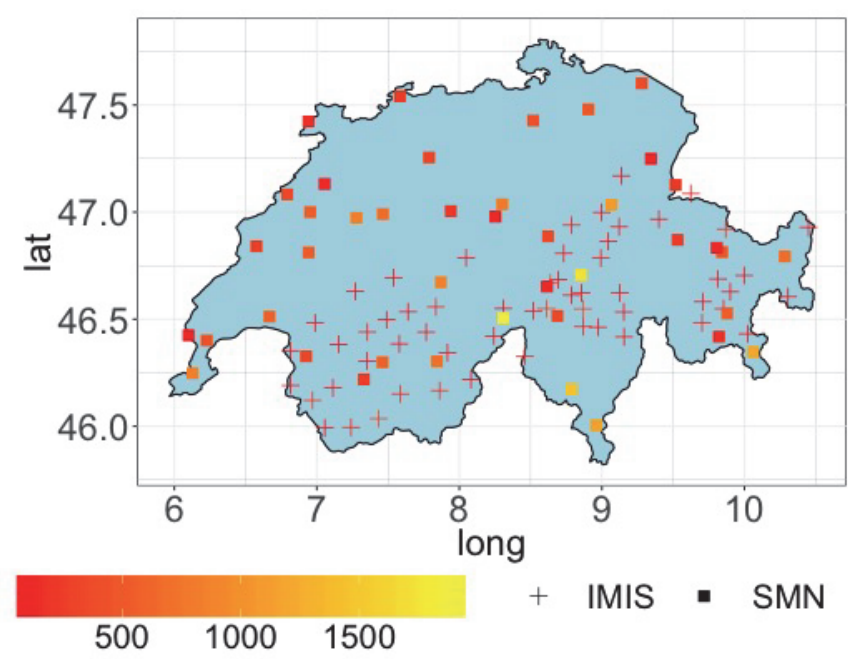

(b) 50 year return level

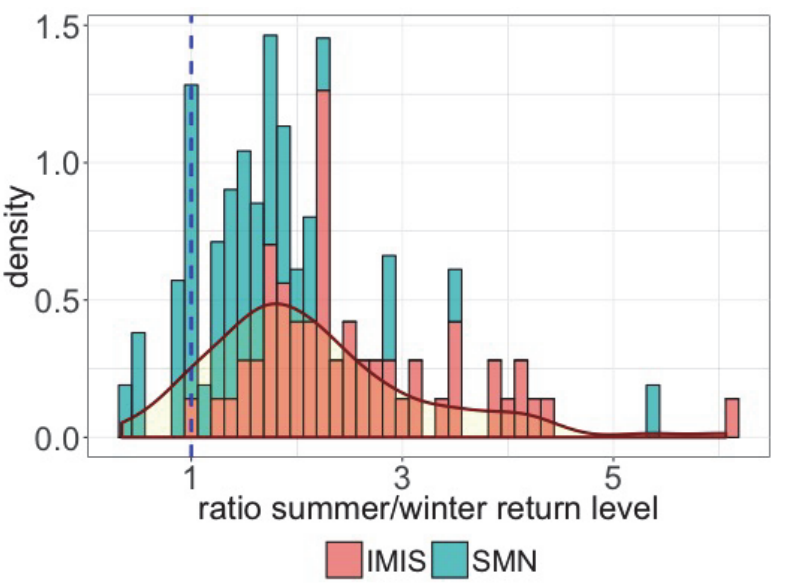

Figure 5: Ratio of return levels in summer vs winter. A value above 1 indicates higher return levels in summer. The series were split into summer and winter, where summer was defined as consisting of the months May to October, and winter as November through April.

Figure 4: Return levels for no power intervals. These represent the no-power 448 production intervals that are to be expected once every $10(50)$ years. of figure 6). These two stations are both located at a hill with a long upwind fetch amidst relatively flat terrain, which may ${ }^{452}$ contribute to their above average wind speeds.

\subsection{Seasonal decomposition}

Switzerland's electricity consumption is higher in winter 456 due to increased heating and lighting demand [3]. Combined ${ }_{457}$ with the characteristics of the hydrological cycle, this leads to a 458 power deficit in winter [63]. It is therefore insightful to look at 459 the return levels for sustained no-power events in the summer ${ }_{460}$ and winter periods separately. To this end, the dataset is split ${ }_{46}$ into summer and winter. This creates yearly interruptions in the ${ }_{462}$ dataset, whereby the average interval length is shortened. As 463 such, these results cannot be directly compared to the overall $4_{464}$ return levels, but only side by side. This is done in figure 5,465 where we see distinctly lower return levels during winter, when ${ }_{466}$ compared to the summer periods. This implies that no-power ${ }_{467}$ periods are -on average- shorter during the winter months.

\subsection{Diurnal patterns}

Figure 7 shows diurnal wind speed profiles for the stations in the SMN network (left) and IMIS network (right). There appear to be two distinct types of profiles, characterised either by an increase in wind speed during the afternoon, or a decrease. The majority of the stations belong to the latter, which can be explained by the diurnal evolution of the boundary layer. The other distinct pattern we see is wind speeds increasing during the afternoon. This occurs mainly at stations in the SMN network (compare fig a and b). In the IMIS network, only two stations display this behaviour. Both are situated at mountain ridges near the upper end of long valleys (Sidelhorn in the Rhone valley and Cho d'Valetta (Bever) at the Inn valley respectively). Long valleys are known to produce so called valley winds, when thermally induced pressure differences cause up-valley flows [18]. Specifically in the Inn valley, pressure differences of up to 5hPA have been reported [67]. The SMN dataset includes more valley stations, and here the afternoon peak in speeds is more common (see fig 7(a)).

\subsubsection{Seasonal decomposition of diurnal patterns.}

The majority of Switzerland's power comes from hydropower, which has a distinct annual cycle, with production peaking in mid-summer, although demand peaks in winter [3]. In a future renewable Swiss power system, high emphasis will be placed on compatibility with this annual hydropower cycle. Although photovoltaic power generation is assumed to play a big role in Switzerland's future electricity supply [56], it also suffers from an annual cycle that is not complementary to that of hydro [3]. Wind power could provide a balancing component to the power supply. We therefore look at the monthly variations in diurnal patterns, by calculating the average diurnal 

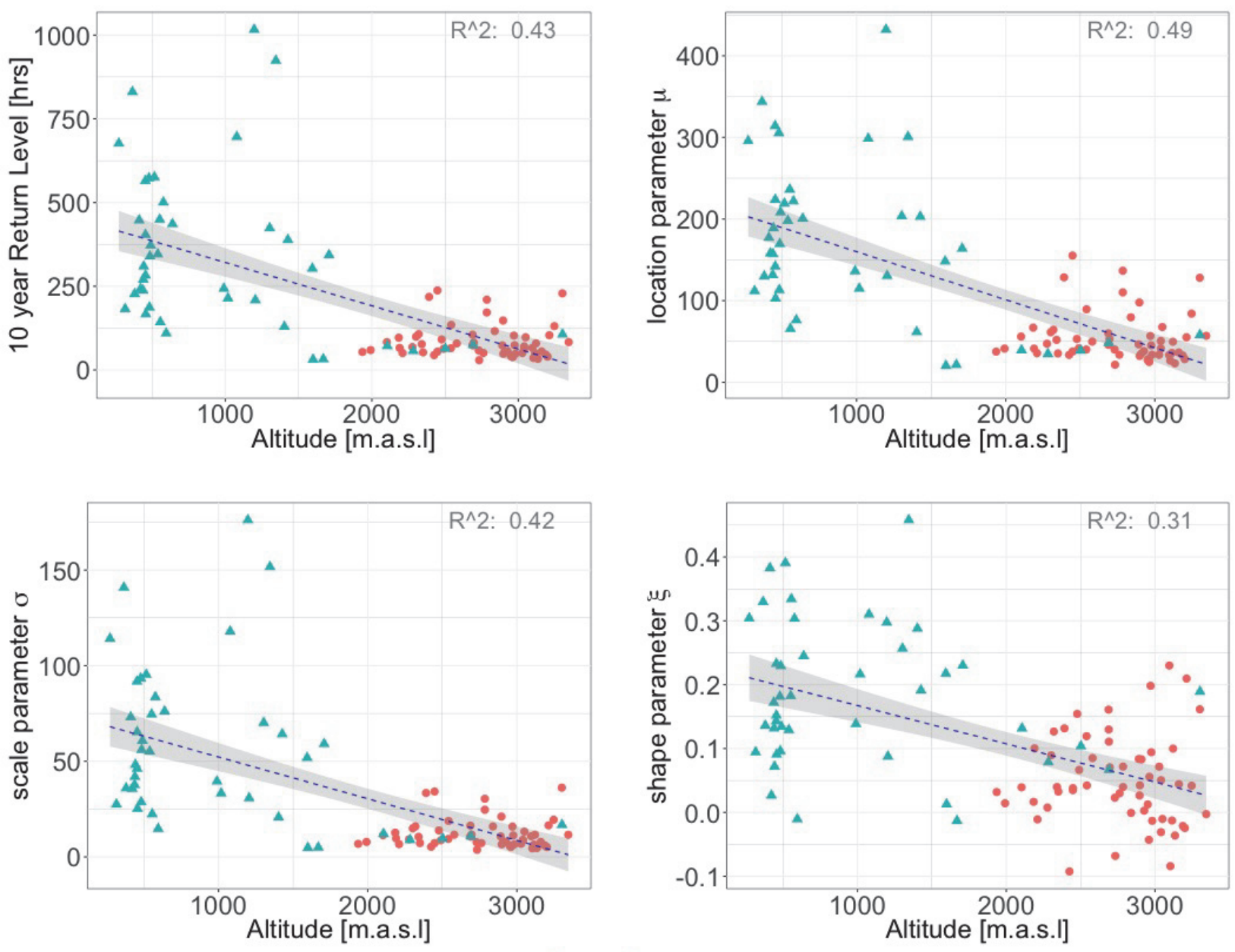

- IMIS $\triangle$ SMN

Figure 6: The 10 year return level (upper left), and the parameters of the GEV distribution, plotted as a function of altitude.

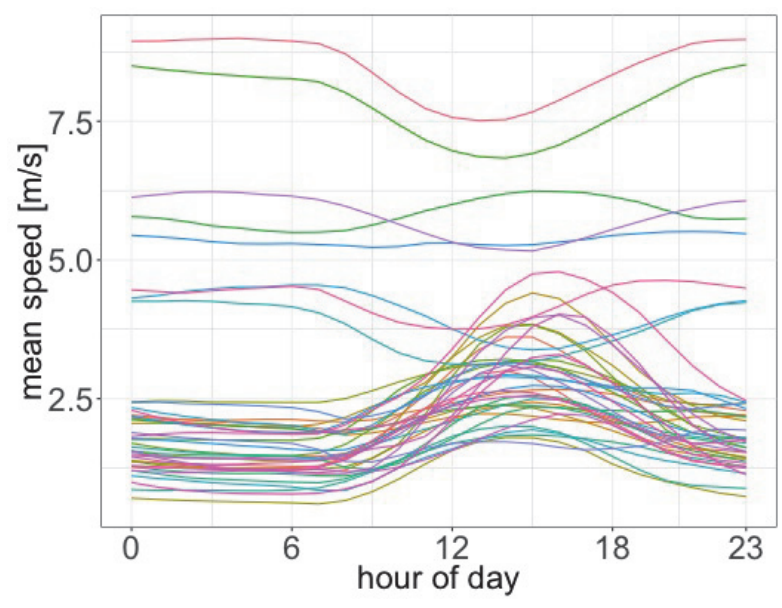

(a) diurnal wind speed, SMN dataset

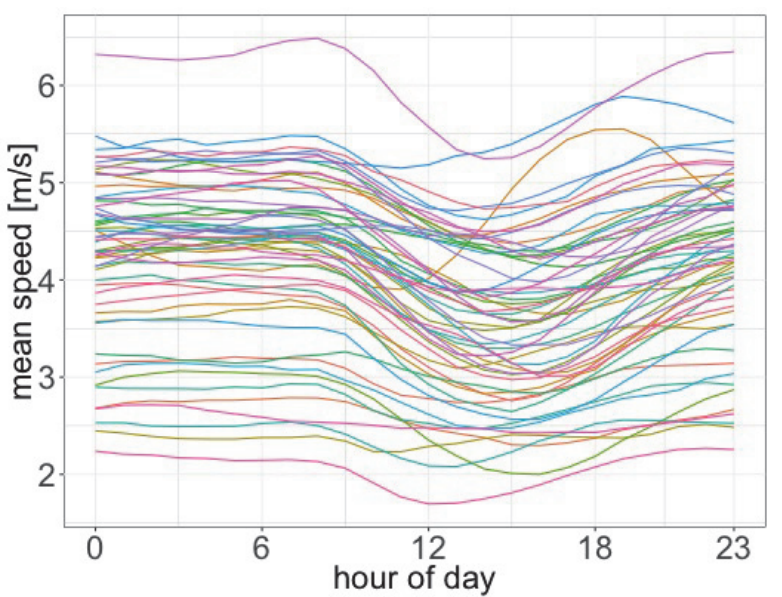

(b) IMIS stations

Figure 7: Diurnal wind speed profiles for the a) SMN stations. b) the IMIS stations. The SMN dataset contains stations at lower elevations, and as such has more stations that display a typical valley wind pattern with wind speeds increasing in the afternoon. In The IMIS dataset with higher elevation stations this behaviour is less common. Times are in UTC ( $+1 \mathrm{hr}$ for Swiss wintertime, +2 for summertime.) 

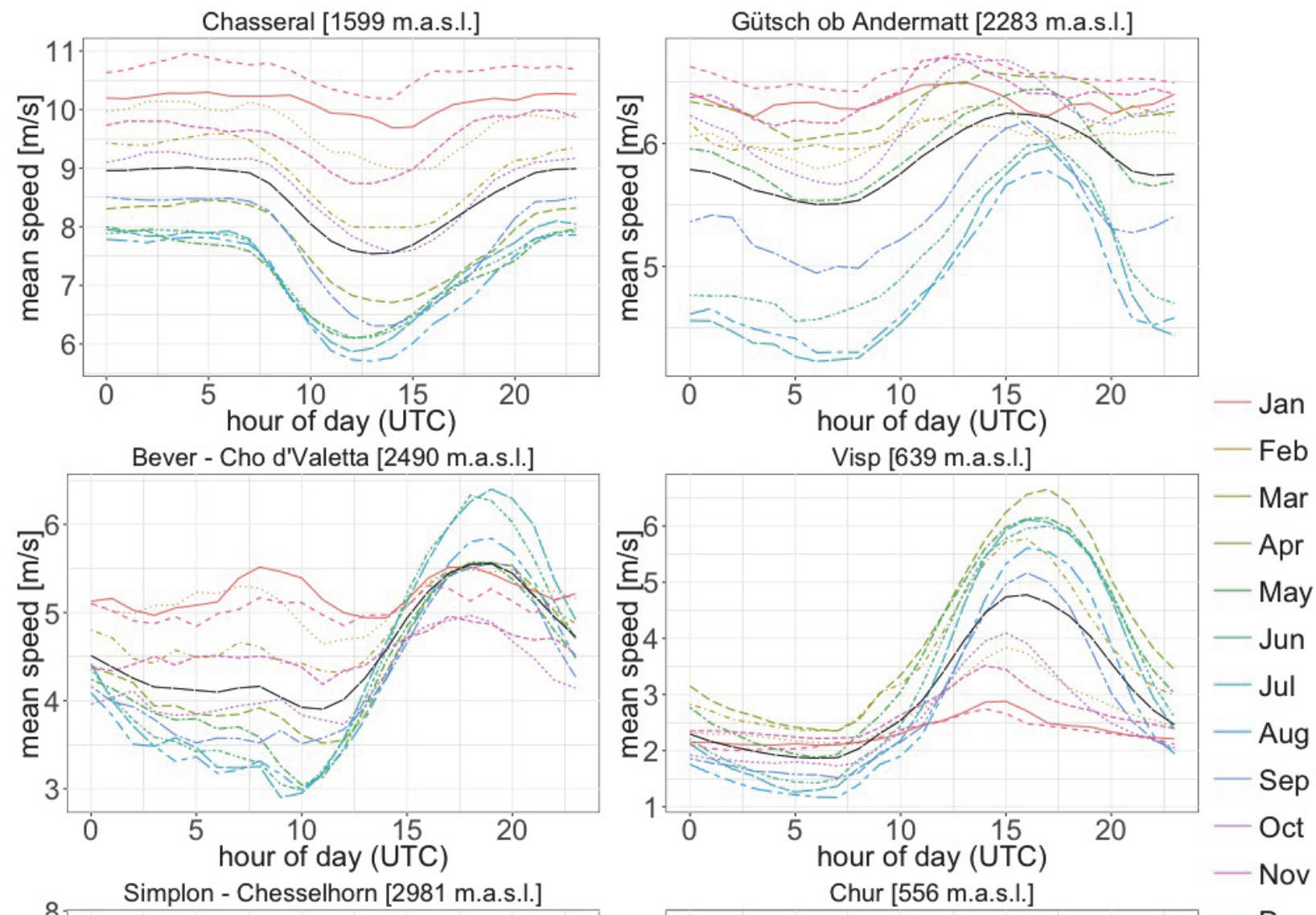

- Feb

- Mar
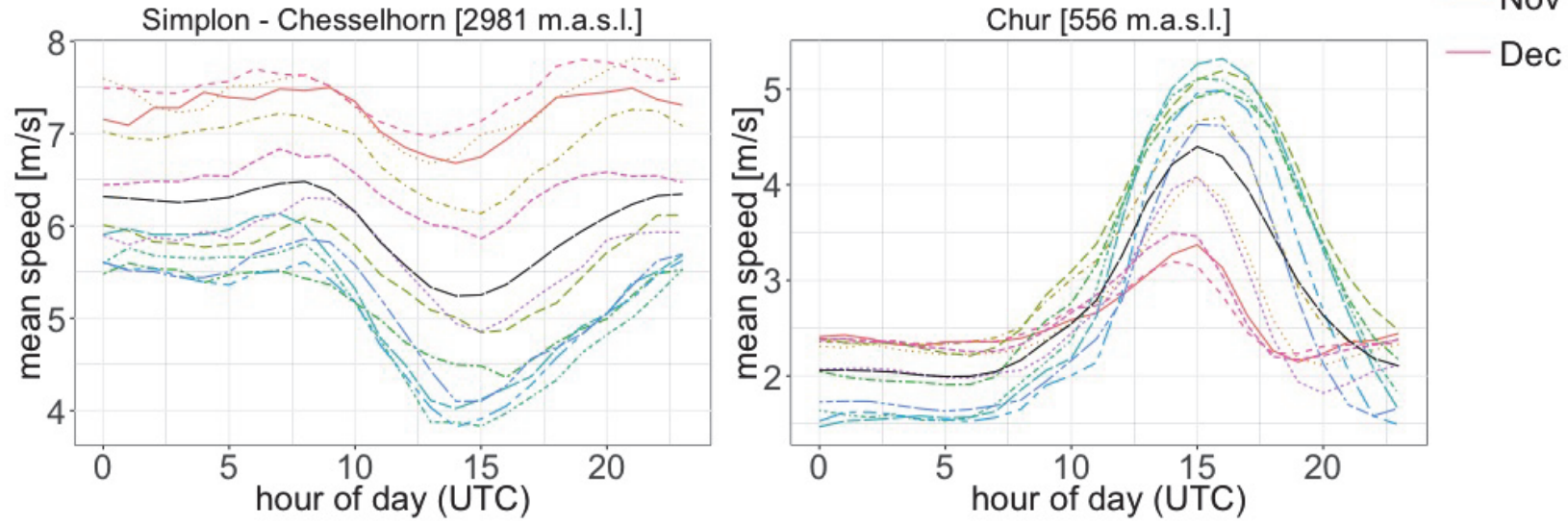

Figure 8: monthly diurnal patterns for the locations Chasseral, Gütsch, Bever Visp, Simplon and Chur. The black dashed line indicates the annual average, the coloured lines represent the months. Times are in UTC $(+1 \mathrm{hr}$ for Swiss wintertime, +2 for summertime.) 


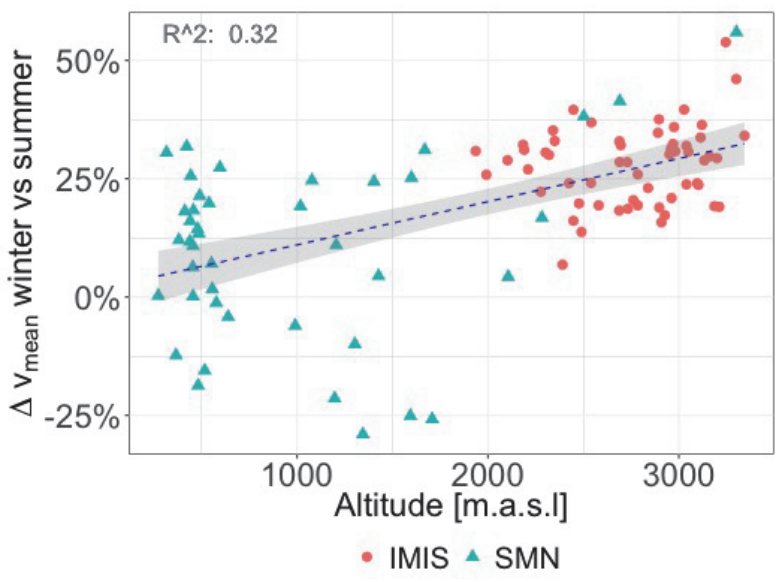

Figure 9: Relative increase in mean speeds in winter compared to summer, as a function of elevation. Higher altitude locations seem -on average- to have relatively higher wind speeds in winter. cycle per month. Figure 8 displays such monthly decomposi-504 tions for 6 selected stations. What is clear in all cases, is that 505 there is significant variation from the annual average diurnal cy-506 cle, displayed by a dashed black line. Examining the stations at507 Gütsch, Bever, Chur and Visp, we see that the increase during the afternoon that is associated with a thermally induced valley wind, mainly occurs in the summer months when irradiance is ${ }^{508}$ high. During winter the peak is significantly less pronounced ${ }_{509}$ at these locations. Similarly for the stations without thermally $y_{510}$ driven winds (Chasseral, and Simplon) we also see a decrease ${ }_{51}$ in intra-daily variation during winter, as profiles become flatter. ${ }_{512}$

\subsection{Elevation}

Mean wind speeds in Europe are reported to be higher in win- ${ }^{515}$ ter [37], which based on our data we can confirm for Switzer-- ${ }^{516}$ land: On average, mean wind speeds in the winter month $s^{517}$ (November through April) are 20,2\% higher than the mean ${ }^{518}$ speeds in summer. However, 11 out of the 99 locations do not ${ }^{519}$ have a higher mean speed in winter. These 'summer-high' sta-5 ${ }^{520}$ tions all display a clear signature of thermally induced winds, ${ }^{521}$ which explains the high summer means. Plotting the relative ${ }^{522}$ difference in seasonal mean speed as a function of elevation, ${ }^{523}$ we see an interesting pattern depicted in figure 9 . The relative ${ }^{524}$ increase in winter compared to summer increases with eleva- ${ }^{525}$ tion.

Higher winter wind speeds could imply favourable condi- ${ }^{527}$ tions for wind farms at higher elevations, although at the same ${ }^{528}$ time air density decreases with elevation, leading to lower ${ }^{529}$ power output. To investigate this we have simulated the power production for each location, including a correction for reduced yield due to air density. The methodology is described in Appendix A. When we plot the power production (corrected for air density) as a function of elevation, we see that there is a clear increase in power production at higher elevations (figure 10). The negative effect that lower air density has on power production seems to be more than offset by higher wind speeds. Also included in this plot is a sensitivity analysis of the effect

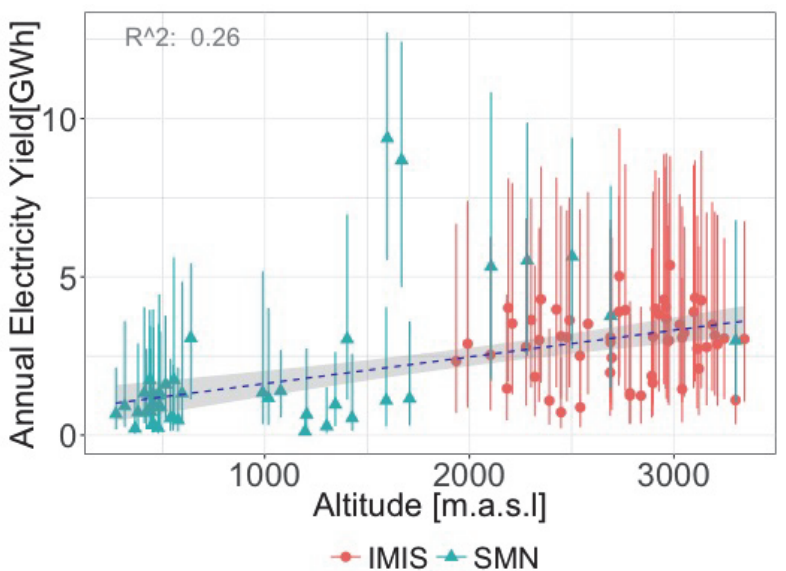

Figure 10: Simulated electricity production as a function of elevation. Higher altitude locations seem -on average- to have relatively higher yield, despite lower air density.

of the wind shear parameter $\alpha$ on the results. The calculation was performed several times with values of $\alpha$ between -0.07 and 0.42 . The resulting spread in the results is indicated with vertical bars. The fit and $\mathrm{R}$ values are for an $\alpha$ of 0.14 .

\section{Sensitivity and Outlook}

In this section we investigate some of the assumptions and uncertainties that may influence the results. A large factor of uncertainty is introduced by the vertical translation of wind speeds. Although it is acknowledged that the value of the wind shear coefficient $\alpha$ varies significantly (see section 2.5 and references therein), no suitable parametrisation has been found. Since the vertical translation is done for the cut-in and cut-out speeds of the turbine, the choice of $\alpha$ will have a direct effect on the value of the (translated) cut-in speed and thus on the length of the intervals outside of the turbine's operating range (and hence the calculated return levels). Similarly, the cut-in and cut-out speeds themselves influence the interval length and return levels. The choice of turbine will therefore also have an effect on the results. Both effects can be captured by varying the cut-in speed and recording the effect on the 10 year return level of sustained no-power periods. The spread of the results is depicted in figure 11, where the most sensitive location (max) and the least sensitive location (min) are shown alongside the average effect. A similar graph (not shown) for the sensitivity to cut-out speeds showed very low sensitivity to cut-out speed variation. 


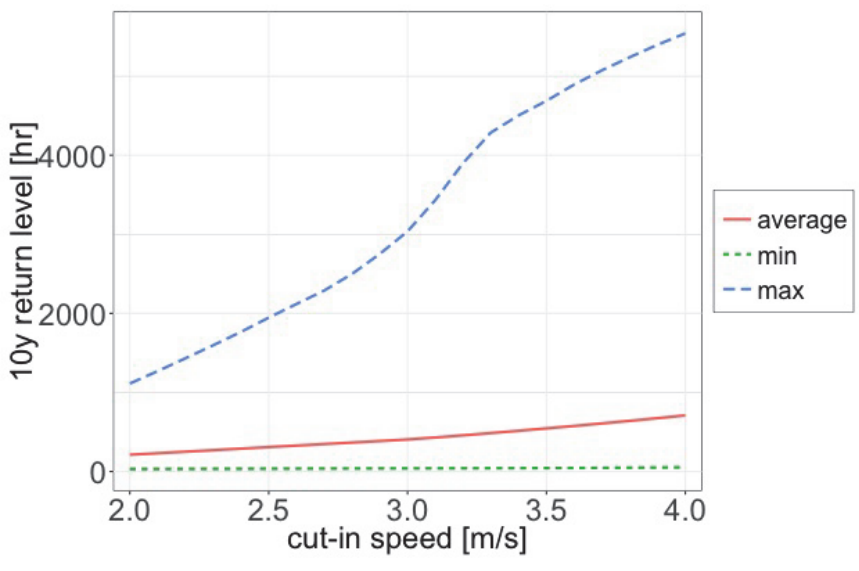

Figure 11: Sensitivity of calculated return levels to cut in speeds

Using hourly wind speed data from two measurement ${ }_{588}$ networks across Switzerland, we have shown that cross-589 correlations as a function of distance between stations are sig- -590 nificantly lower in Switzerland than values reported in litera-591 ture for Europe and the US. The discrepancy with previously $y_{592}$ reported values can easily be understood from the complex ter-593 rain that makes up much of Switzerland's surface. This influ-594 ences wind speed characteristics significantly, as can also be ${ }_{595}$ seen in other results. The implications for wind power pro-596 duction may however be positive: Smoothing the output from ${ }_{597}$ combinations of wind farms can in Switzerland be achieved ${ }_{598}$ over much shorter distances than those commonly reported $\mathrm{in}_{599}$ literature. This holds for any country with complex terrain in- 600 fluencing the wind climate. Furthermore, capacity credit -the 601 ability to displace conventional generating capacity- increases ${ }_{602}$ with increased smoothing of the combined wind power output [27]. Because of this, the capacity credit of wind power will be 603 higher with lower correlation.

We have analysed the length of periods where the wind speed ${ }_{605}$ is outside the operating range of the Enercon E82 turbine for ${ }_{600}$ 99 wind stations across Switzerland. An extreme value distri-607 bution was fitted to each of these length records, to allow for 608 the calculation of return levels for return periods of 10 and $50_{609}$ years. These return levels show great spatial variability, yet ${ }_{610}$ return levels clearly decrease as the elevation of the stations $s_{611}$ increases (figure 6), which implies that wind farms that are lo-612 cated at higher elevation are less likely to suffer long periods ${ }_{613}$ without power production. A decomposition of the return lev-614 els for summer and winter periods showed significantly lower ${ }_{615}$ return levels in winter, indicating that the likelihood of persis-616 tent periods where no wind power can be produced are lower ${ }_{617}$ for almost all locations in winter. This is beneficial for Switzer-618 land, since it has an electricity deficit in winter, and a future ${ }_{619}$ renewables-based power system is likely to be under the great-620 est stress during the winter months, as is the current system. $\quad{ }_{621}$

We have confirmed that wind speeds are on average indeed 622 higher in winter, although we have also been able to show that 623 there are notable exceptions, with implications for wind power624 generation. While many of the measurement locations at mountain ridges are exposed to rather free tropospheric wind conditions during night and much of the day, the developing thermal up-slope and up-valley winds are able to create a local boundary layer. This boundary layer prevents the penetration of high wind speeds to ground level. Hence the majority of the measurement stations display a decrease in wind speed during the afternoon. Contrarily, long valleys experience rather low wind speeds during night time and most of the day. With strong solar irradiation however, thermally induced pressure differences can cause up-valley winds. As the temperature increases during the day, wind speeds increase with a peak between 3 p.m. and $8 \mathrm{p} . \mathrm{m}$. These peaks are more pronounced during the summer months when solar irradiation is higher, whereas in winter they can be virtually non-existent. For the 88 of the 99 stations in our dataset, the mean wind speed is higher in winter. The few stations that have higher mean wind speed in summer are all found at the bottom of valleys, where the strong radiative heating in summer creates the afore-described increase in wind speed.

The usefulness of these valley stations for wind electricity production is limited since their pronounced peak mainly occurs during summer, when the demand for electricity is lower and hydropower is abundantly available. Moreover, as electricity production from PV is projected to increase both in Switzerland and in the neighbouring countries, in a future, highly renewable Europe there will likely be a surplus of power at daytime during summer.

For all but these few valley stations, not only is the mean wind speed higher in winter, but the relative difference between winter and summer is also more pronounced with increasing elevation (figure 9). Moreover, power production also appears to increase with elevation (figure 10), despite the negative effects of lower air density on electricity yield.

\subsection{Implications and Outlook}

Given Switzerland's power deficit in winter and it's intended nuclear phase-out, electricity sources that are either dispatchable or have a seasonal pattern to complement this deficit are called for. However apart from biomass, all currently feasible dispatchable technologies are fossil based and as such are questionable in view of climate change. Amongst the currently mature renewable technologies, wind power has a highly favourable seasonal profile. We've been able to show that this seasonal pattern appears more pronounced at altitude, and that wind power in long valleys subject to thermally induced wind speed-up has an unfavourable seasonal profile. Annual average wind speeds can mask such important dynamics, which can become important as renewables penetrate the electricity market. Feed-in tariffs, which currently allow profitable power production from such valley wind farms will eventually be abolished as wind power reaches grid parity, at which point market prices reflecting demand will determine the profitability. Given our results it is highly debatable wether wind farms that mainly produce during periods of low (residual) demand should be subsidised in this way, especially as we have shown that high elevation locations are able to provide power at times of high 
demand. In shaping Switzerland's energy transition, account-682 ing for these dynamics may prevent costly mishaps. The re-683 sults here underline the need for further research into seasonal- ${ }_{685}^{684}$ dependent feed-in tariffs for wind power.

There are still a lot of open questions however. For one, the 687 wind climate in alpine terrain is extremely hard to map. Where ${ }^{688}$ in flat terrain correlations are relatively strong over long dis- ${ }^{689}$ tances, facilitating extrapolation of measurements and models, ${ }_{691}$ in the complex terrain of the Alps this is challenging. Attaining 692 an accurate overview of the wind climate in the Alps would re- ${ }^{693}$ quire either a drastic (and possibly unrealistic) increase in mea- ${ }_{695}^{694}$ surement stations, or huge advances in computational power, ${ }_{696}$ as the resolution required to accurately model the flow in this ${ }^{697}$ terrain should be high enough to capture all relevant terrain fea- ${ }^{698}$ tures. Perhaps a hybrid approach, where high resolution mod- ${ }_{700}^{699}$ elling of specific locations can provide an estimate of the Alpine ${ }_{701}$ potential by extrapolation to similar features, is the first step to ${ }^{702}$ take.

Another aspect that has not been taken into consideration ${ }_{705}^{704}$ here is the performance of wind turbines in Alpine environ-706 ments. Extreme temperatures can influence the material prop-707 erties of various components [4], while surface roughness has ${ }_{709}^{708}$ been linked to an increase in fatigue loads [49], and icing of the ${ }_{710}^{709}$ rotor blades can cause energy losses of ca $2 \%$ [2]. Although ${ }_{711}$ an algorithm to estimate icing frequencies in Switzerland has ${ }^{712}$ been developed, the authors acknowledge that model resolution ${ }_{714}^{713}$ is too low to capture local terrain features in the Alps that de- ${ }_{715}$ termine icing frequencies [34]. Combining al these elements to ${ }^{716}$ attain insight into the failure probabilities of wind turbines $\mathrm{in}^{717}$ alpine terrain, will therefore be an important next step on the ${ }_{719}^{718}$ road to extensive wind power deployment in the Swiss Alps. $\quad{ }_{720}$

\section{Acknowledgements}

This research is funded by the Swiss National Science foun- ${ }^{724}$ dation under the National Research Programme NRP 70 'En-726 ergy Turnaround'. We would further like to thank Christoph ${ }^{727}$ Marty and Michel Bovey for their help with the data acquisi- ${ }_{729}$ tion.

\section{References}

[1] Arbeitsgruppe Erneuerbare Energienstatistik. Zeitreihen zur Entwicklung der erneuerbaren Energien in Deutschland. 2016.

[2] Sarah Barber, Ndaona Chokani, and Reza S. Abhari. Assessment of Wind ${ }_{736}^{736}$ Turbine Performance in Alpine Environments. Wind Engineering, $35:_{738}$ 313-328, 2011. ISSN 0309-524X. doi: 10.1260/0309-524X.35.3.313.

[3] S Bartlett, B Kruyt, A Kahl, and M Lehning. Risks and Reliability in $\mathrm{a}_{740}$ Fully Renewable Switzerland. Esrel, pages 4251-4256, 2015.

[4] Lorenzo Battisti. Wind Turbines in Cold Climates: Icing Impacts and ${ }_{742}^{741}$ Mitigation Systems. Springer, Trento, 2015. ISBN 9783319051901.

[5] BFE. Energy Strategy 2050, 2016. URL http://www .bfe.admin.ch/ ${ }^{743}$ themen/00526/00527/?lang=en.

[6] Juliette Blanchet and Anthony C. Davison. Spatial modeling of extreme ${ }_{745}^{745}$ snow depth. Annals of Applied Statistics, 5(3):1699-1725, 2011. ISSN 747 19326157. doi: 10.1214/11-AOAS464.

[7] Juliette Blanchet and M. Lehning. Mapping snow depth return lev- ${ }_{748}^{748}$ els: smooth spatial modeling versus station interpolation. Hydrol- ${ }_{750}^{749}$ ogy and Earth System Sciences, 14(12):2527-2544, dec 2010. ISSN 1607-7938. doi: 10.5194/hess-14-2527-2010. URL http://www. 752 hydrol-earth-syst-sci.net/14/2527/2010/.
[8] Juliette Blanchet, C. Marty, and M. Lehning. Extreme value statistics of snowfall in the Swiss Alpine region. Water Resources Research, 45(5): n/a-n/a, may 2009. ISSN 00431397. doi: 10.1029/2009WR007916. URL http://doi.wiley.com/10.1029/2009WR007916.

[9] Arno J Brand, Joachim Peinke, and Jakob Mann. Turbulence and wind turbines. Journal of Physics: Conference Series, 318(7):072005, 2011. ISSN 1742-6596. doi: 10.1088/1742-6596/318/7/072005.

[10] Anne Sjoerd Brouwer, Machteld Van Den Broek, Ad Seebregts, and André Faaij. Impacts of large-scale Intermittent Renewable Energy Sources on electricity systems, and how these can be modeled. Renewable and Sustainable Energy Reviews, 33:443-466, 2014. ISSN 13640321. doi: 10.1016/j.rser.2014.01.076. URL http://dx.doi.org/10.1016/ j.rser.2014.01.076.

[11] Anne Sjoerd Brouwer, Machteld van den Broek, Ad Seebregts, and André Faaij. Operational flexibility and economics of power plants in future low-carbon power systems. Applied Energy, 156:107-128, 2015. ISSN 03062619. doi: 10.1016/j.apenergy.2015.06.065. URL http://dx.doi.org/10.1016/j.apenergy.2015.06.065.

[12] Anne Sjoerd Brouwer, Machteld van den Broek, William Zappa, Wim C. Turkenburg, and André Faaij. Least-cost options for integrating intermittent renewables in low-carbon power systems. Applied Energy, 161:4874, 2016. ISSN 03062619. doi: 10.1016/j.apenergy.2015.09.090. URL http://dx.doi.org/10.1016/j . apenergy . 2015.09.090.

[13] Bundesamt für Energie. Schweizerische Elektrizitätsstatistik 2014 pages 1-56, 2015. URL https://www.bundespublikationen. admin.ch/cshop $\left\{\backslash_{-}\right\}$bbl/b2c/init/(cquery=*805.005.14*)/. do? shopId=BBL00001DE $\{\backslash \&\}$ language=DE.

[14] U. Bunse and H. Mellinghoff. Influences of Vertical Wind Profiles on Power Performance Measurements U. pages 1-5.

[15] Yoreley Cancino-Solórzano, Antonio J. Gutiérrez-Trashorras, and Jorge Xiberta-Bernat. Analytical methods for wind persistence: Their application in assessing the best site for a wind farm in the State of Veracruz, Mexico. Renewable Energy, 35(12):2844-2852, 2010. ISSN 09601481. doi: 10.1016/j.renene.2010.05.008. URL http://dx.doi. org/10.1016/j.renene. 2010.05.008.

[16] René Cattin, Beat Schaffner, Stefan Kunz, and Robert Horbaty. Wind measurements and modeling in the Swiss Alps. pages 1-8, 2003.

[17] P Ceppi and C Appenzeller. Extreme Value Analysis of Wind Speed Observations over Switzerland. Technical Report 219, 2008.

[18] Fotini Katopodes Chow. Mountain Weather Research and Forecasting: Recent Progress and Current Challenges. 2013. ISBN 9789400740976.

[19] Andrew Clifton, M H Daniels, and M Lehning. Effect of winds in a mountain pass on turbine performance. (August 2013):1543-1562, 2014. doi: $10.1002 /$ we.

[20] Stuart Coles. An introduction to statistical modeling of extreme values. 2001. ISBN 1-85233-459-2. doi: 10.1007/978-1-4471-3675-0.

[21] Stuart Coles and Anthony Davison. Statistical Modelling of Extreme Values. 2008. URL http://www.cces.ethz.ch/projects/hazri/ EXTREMES/talks/colesDavisonDavosJan08.pdf.

[22] Giorgio Corbetta. EWEA Wind energy scenarios for 2030. Ewea, pages $1-8,2015$.

[23] A. DeMarrais, Gerard. Wind-Speed Profiles At Brookhaven National Laboratory. Journal of Meteorology, 16:181-190, 1958.

[24] Caroline Draxl and Georg J. Mayr. Meteorological wind energy potential in the Alps using ERA40 and wind measurement sites in the Tyrolean Alps. In EWEC2009, 2009.

[25] Jérome Dujardin, Annelen Kahl, Bert Kruyt, Stuart Bartlett, and Michael Lehning. Interplay between photovoltaic, wind energy and storage hydropower in a fully renewable Switzerland. Manuscript submitted for publication., 2016.

[26] S Emeis. How Well Does a Power Law Fit to a Diabatic Boundary-Layer Wind Profile ? (26):59-62, 2005.

[27] Cornel Ensslin, Michael Milligan, Ieee Hannele Holttinen, Mark O Malley, and Andrew Keane. Current Methods to Calculate Capacity Credit of Wind Power. IEEE, pages 1-3, 2008.

[28] Christophe Etienne, Anthony Lehmann, Stéphane Goyette, Juan-Ignacio Lopez-Moreno, and Martin Beniston. Spatial Predictions of Extreme Wind Speeds over Switzerland Using Generalized Additive Models. Journal of Applied Meteorology and Climatology, 49(9):1956-1970, 2010. ISSN 1558-8424. doi: 10.1175/2010JAMC2206.1.

[29] Enzo Fanone, Andrea Gamba, and Marcel Prokopczuk. The case of neg- 
ative day-ahead electricity prices. Energy Economics, 35(May 2008):22-824 34, 2013. ISSN 01409883. doi: 10.1016/j.eneco.2011.12.006. URL825 http://dx.doi.org/10.1016/j.eneco.2011.12.006.

[30] R. N. Farrugia. The wind shear exponent in a Mediterranean island cli-827 mate. Renewable Energy, 28(4):647-653, 2003. ISSN 09601481. doi:828 10.1016/S0960-1481(02)00066-6.

[31] Ebubekir Frtn, Önder Güler, and Seyit Ahmet Akda. Investigation of 830 wind shear coefficients and their effect on electrical energy generation.83 Applied Energy, 88(11):4097-4105, 2011. ISSN 03062619. doi: 10.832 1016/j.apenergy.2011.05.025

[32] George Galanis. Smoothing out the wind power production patterns by 834 connecting different countries within Europe. MSc Thesis. PhD thesis, 835 Utrecht, 2014.

[33] Giebel. On the Benefits of Distributed Generation of Wind Energy in837 Europe. PhD thesis, 2000.

[34] Thomas Grünewald, Silke Dierer, Felix Fundel, and Michael Lehning.839 Mapping frequencies of icing on structures in Switzerland. Journal of 840 Wind Engineering and Industrial Aerodynamics, 108:76-82, 2012.

[35] L De Haan and A Ferreira. Extreme value theory: an introduction.84 Springer, 2007. ISBN 9780387239460.

[36] Berthold Hahn, Michael Durstewitz, and Kurt Rohrig. Reliabil-844 ity of Wind Turbines. Wind Energy, pages 1-4, 2007. doi: 10.845 1007/978-3-540-33866-6_62. URL http://link.springer.com/846 content/pdf/10.1007/978-3-540-33866-6\{\_\}62.pdf.

37] Dominik Heide, Lueder von Bremen, M. Greiner, Clemens Hoffmann, 848 Markus Speckmann, and Stefan Bofinger. Seasonal optimal mix of wind 849 and solar power in a future, highly renewable Europe. Renewable Energy,850 35(11):2483-2489, nov 2010. ISSN 09601481. doi: 10.1016/j.renene.851 2010.03.012. URL http://linkinghub.elsevier.com/retrieve/852 pii/S0960148110001291.

38] Lion Hirth. The benefits of flexibility: The value of wind energy with hy-854 dropower. Applied Energy, 181:210-223, 2016. ISSN 03062619. doi: 10.855 1016/j.apenergy.2016.07.039. URL http://linkinghub.elsevier . 856 com/retrieve/pii/S0306261916309801.

[39] Hannele Holttinen. Hourly wind power variations in the nordic countries.858 Wind Energy, 8(2):173-195, 2005. ISSN 10954244. doi: 10.1002/we.859 144.

[40] James Honaker, Gary King, and Matthew Blackwell. AMELIA II : A86 Program for Missing Data. Journal Of Statistical Software, 45(7):1-54,862 2011. ISSN 15487660. doi: 10.1.1.149.9611. URL http://gking. 863 harvard.edu/amelia/.

[41] James Honaker, Gary King, and Matthew Blackwell. AMELIA II * As6 Program for Missing Data, 2015. URL http://gking. harvard.edu/866 amelia/.

[42] Warren Katzenstein, Emily Fertig, and Jay Apt. The variability of inter-868 connected wind plants. Energy Policy, 38(8):4400-4410, 2010. ISSN869 03014215. doi: 10.1016/j.enpol.2010.03.069. URL http://dx.doi. 870 org/10.1016/j.enpol.2010.03.069.

[43] Janina C. Ketterer. The Impact of Wind Power Generation on the Elec-872 tricity Price in Germany. 2012.

[44] Kasim Koçak. A method for determination of wind speed persistence and 874 its application. Energy, 27(10):967-973, 2002. ISSN 03605442. doi:875 10.1016/S0360-5442(02)00033-6

[45] Kasim Koçak. Practical ways of evaluating wind speed persistence. En-877 ergy, 33(1):65-70, 2008. ISSN 03605442. doi: 10.1016/j.energy.2007.878 07.010 .

[46] M. L. Kubik, P. J. Coker, J. F. Barlow, and C. Hunt. A study into thes8 accuracy of using meteorological wind data to estimate turbine generation88 output. Renewable Energy, 51:153-158, 2013. ISSN 09601481. doi:882 10.1016/j.renene.2012.08.084. URL http://dx.doi.org/10.1016/883 j.renene.2012.08.084.

[47] Mohamed Laib and Mikhail Kanevski. Spatial Patterns of Wind Speed 885 Distributions in Switzerland. (November), 2016. URL http://arxiv . 886 org/abs/1609.05012.

[48] Paul G. Leahy and Eamon J. McKeogh. Persistence of low wind 88 speed conditions and implications for wind power variability. Wind $E n-889$ ergy, 16(4):575-586, may 2013. ISSN 10954244. doi: 10.1002/we.890 1509. URL http://onlinelibrary . wiley.com/doi/10.1002/we. 891 1608/fullhttp://doi.wiley.com/10.1002/we.1509.

[49] S Lee, M Churchfield, P Moriarty, and J Jonkman. Atmospheric and wake turbulence impacts on wind turbine fatigue loadings. Proc. of the 50th AIAA Aerospace Sciences Meeting, (NREL/CP-5000-53567), 2012. URL http: //arc . aiaa.org/doi/pdf/10.2514/6.2012-540.

[50] Michael Lehning, Perry Bartelt, Bob Brown, Tom Russi, Urs St??ckli, and Martin Zimmerli. SNOWPACK model calculations for avalanche warning based upon a new network of weather and snow stations. Cold Regions Science and Technology, 30(1-3):145-157, 1999. ISSN 0165232X. doi: 10.1016/S0165-232X(99)00022-1.

[51] Peter D. Lund, Juuso Lindgren, Jani Mikkola, and Jyri Salpakari. Review of energy system flexibility measures to enable high levels of variable renewable electricity. Renewable and Sustainable Energy Reviews, 45: 785-807, 2015. ISSN 13640321. doi: 10.1016/j.rser.2015.01.057. URL http://dx.doi.org/10.1016/j.rser.2015.01.057.

[52] MeteoSchweiz. Automatisches Messnetz, 2016. URL http://www . meteoschweiz.admin.ch/home/mess-und-prognosesysteme/ bodenstationen/automatisches-messnetz.html.

[53] MeteoTest. Windenergie-Daten der Schweiz. URL http:// wind-data.ch/messdaten/.

[54] NASA. U.S. Standard Atmosphere, 1976. URL http://ntrs .nasa. gov/archive/nasa/casi.ntrs.nasa.gov/19770009539.pdf.

[55] Jp Palutikof, Bb Brabson, Dh Lister, and St Adcock. A review of methods to calculate extreme wind speeds. Meteorological, 6:119-132, 1999. ISSN 1469-8080. doi: 10.1017/S1350482799001103. URL http: //journals . cambridge.org/abstract \{\_\}S1350482799001103.

[56] Prognos. Die Energieperspektiven für die Schweiz bis 2050. 2012.

[57] Shafiqur Rehman and Naif M. Al-Abbadi. Wind shear coefficients and their effect on energy production. Energy Conversion and Management, 46(15-16):2578-2591, 2005. ISSN 01968904. doi: 10.1016/j.enconman. 2004.12.005.

[58] Rp-online.de. Stromnetz unter Druck: Starkwind drückt Leistung von 22 Akw ins Netz, 2015. URL http://www.rp-online.de/wirtschaft/ starkwind-drueckt-leistung-von-22-akw-ins-netz-aid-1. 4981986.

[59] E. Simiu and N. a. Heckert. Extreme Wind Distribution Tails: A Peaks over Threshold Approach. Journal of Structural Engineering, 122(5):539-547, 1996. ISSN 0733-9445. doi: 10.1061/(ASCE) 0733-9445(1996)122:5(539).

[60] SLF. Measurement and Information System (IMIS), 2016. URL http://www.slf.ch/ueber/organisation/warnung \{】_ \} praevention/warn $\left\{\backslash_{\text {_ }}\right\}$ informationssysteme/messnetze $\left\{\backslash_{\text {_ }}\right.$ \}daten/imis/index $\left\{\backslash \_\right.$EN.

[61] R1 Smith. Statistics of extremes, with applications in environment, insurance, and finance. Monographs on Statistics and Applied Probability, (March):1-62, 2004. ISSN 0960-6696.

[62] Mária Süveges and Anthony C Davison. Model misspecification in peaks over threshold analysis. The Annals of Applied Statistics, 4(1):203-221, 2010. ISSN 1932-6157. doi: 10.1214/09-AOAS292. URL http:// arxiv.org/abs/1010.1357.

[63] Swissgrid. Grid Data 2014. Technical report, 2014.

[64] Luciano Telesca, Michele Lovallo, and Mikhail Kanevski. Power spectrum and multifractal detrended fluctuation analysis of high-frequency wind measurements in mountainous regions. Applied Energy, 162 (JANUARY):1052-1061, 2016. ISSN 03062619. doi: 10.1016/j. apenergy.2015.10.187.

[65] E. Thibaud, R. Mutzner, and a. C. Davison. Threshold modeling of extreme spatial rainfall. Water Resources Research, 49(8):4633-4644, 2013. ISSN 00431397. doi: 10.1002/wrcr.20329.

[66] Falko Ueckerdt, Robert Brecha, and Gunnar Luderer. Analyzing major challenges of wind and solar variability in power systems. Renewable Energy, 81:1-10, 2015. ISSN 18790682. doi: 10.1016/j.renene.2015.03. 002. URL http://dx.doi .org/10.1016/j.renene. 2015.03.002.

[67] I. Vergeiner and E. Dreiseitl. Valley winds and slope winds - Observations and elementary thoughts. Meteorology and Atmospheric Physics, 36(1-4): 264-286, 1987. ISSN 01777971. doi: 10.1007/BF01045154.

[68] D Villanueva, J L Pazos, and A Feijóo. Analysis of the relationship between distance and wind speed correlation in complex terrain cases. Wind Energy, pages 2011-2011, 2011.

[69] Rudolf O. Weber and Markus Furger. Climatology of near-surface wind patterns over Switzerland. International Journal of Climatology, 21:809_ 827, 2001. ISSN 08998418. doi: 10.1002/joc.667. 


\section{Appendix A. air density and altitude}

With increasing altitude, air density decreases and as such, the momentum that can be extracted from the air by a turbine is lower. The energy produced at similar wind speeds is therefore lower at altitude, and for a country such as Switzerland, this could be significant. To investigate this effect on power production, we calculate a correction factor to account for the differences in air density at a certain altitude.

The power that can be extracted from the wind is given by

$$
P=\frac{1}{2} \rho A v^{3}
$$

where $\rho$ is the air density, $A$ is the rotor swept area, and $v$ the wind speed. The air density $\rho$ in its turn is a function of pressure $p$, Temperature $T$ (and humitdity):

$$
\rho=\frac{p M}{R T}
$$

with $M$ the molar mass and $R$ the ideal gas constant. Both pressure and temperature can be expressed as a function of altitude $h[54]$

$$
\begin{gathered}
p=p_{0}\left(1-\frac{L h}{T_{0}}\right)^{\frac{g M}{R L}} \\
T=T_{0}-L h
\end{gathered}
$$

where $p_{0}, T_{0}$ are the pressure and temperature at sea level, respectively; $L$ is an average constant representing the temperature lapse rate $(0.0065 \mathrm{~K} / \mathrm{m})$, and $g$, the gravitational constand $\left(9.80665 \mathrm{~m} / \mathrm{s}^{2}\right)$. Combining A.5, A.3 and A.4 we obtain an approximate correction factor for the power production at altitude $h$ compared to sea level:

$$
\frac{\rho(h)}{\rho_{0}}=\left(1-\frac{L h}{T_{0}}\right)^{\frac{g M}{R L}-1}
$$

As temperature varies during the course of the day, the air density is not constant [57]. However, here we neglect diurnal fluctuations in air density. 